\title{
Eagle sendromu: olgu bildirimi
}

\author{
Nilüfer Ersan, * Mehmet İlgüy, Dilhan İlgüy \\ Ağız, Diş ve Çene Radyolojisi Anabilim Dalı, Yeditepe \\ Üniversitesi Diş Hekimliği Fakültesi, İstanbul, Türkiye
}

\section{Özet}

TANITIM: Eagle sendromu, kulak ve temporomandibular eklem bölgesine doğru yayılan, yüz ve boyun ağrısı şeklinde görülen, uzun stiloid çıkıntı veya kalsifiye stilohyoid ligamentin semptomatik halidir.

OLGU BiLdiRimi: 43 yaşındaki kadın hasta 1 yıldır boynun sağ tarafında, mandibulanın arkasından boynun yan tarafına ve kulağa doğru uzanan, tek taraflı, zaman zaman yutma güçlüğüne yol açan, yabancı cisim hissi veren ve boyun hareketlerinde kısıtlıığa neden olan ağrı şikayeti ile Dentomaksillofasiyal Radyoloji kliniğimize başvurdu. Sistemik hastalığı bulunmayan hastanın dental anamnezinde temporomandibuler eklem bozukluğu nedeniyle tedavi görmekte olduğu saptandı. Klinik muayenede tonsiller fossa palpasyonunda ağrının arttığı belirlendi. Rutin tarama için alınan panoramik radyografide çift taraflı uzun stiloid çıkıntı gözlendi. Konik ışınlı bilgisayarlı tomografide de stiloid ligamentin sağda $71.5 \mathrm{~mm}$, solda $69.6 \mathrm{~mm}$ ölçülen çift taraflı kalsifikasyonu izlendi ve hastaya Eagle sendromu tanısı konuldu. Hasta cerrahi rezeksiyon için Kulak-BurunBoğaz kliniğine yönlendirildi. Uzun stiloid çıkıntının cerrahi olarak kısaltılması ile hastalığın semptomlarında iyileşme sağlandı.

Sonuç: Baş-boyun bölgesinde sebebi bulunamayan şikayetlerin varlığında tedavi protokolünü değiştirebilmesi nedeniyle Eagle Sendromu ayırıcı tanıda göz önünde bulundurulmalıdır.

Anahtar Kelimeler: Disfaji; Eagle sendromu; konik ışınlı bilgisayarlı tomografi

KaynaK GöStermek İçin: Ersan N, İlgüy M, iligüy D. Eagle sendromu: olgu bildirimi. Acta Odontol Turc 2016;33(1):30-4

ЕрітӧR: Güven Kayaoğlu, Gazi Üniversitesi, Ankara, Türkiye

YAYIN HAKKI: (C) 2016 Ersan ve ark. Bu eserin yayın hakkı Creative Commons Attribution License ile ruhsatlandırılmıştır. Sınırsız kullanım, dağıtım ve her türlü ortamda çoğaltım, yazarlar ve kaynağın belirtilmesi kaydıyla serbesttir.

[Abstract in English is at the end of the manuscript]

Makale gönderiliş tarihi: 10 Haziran 2014; Yayına kabul tarihi: 16 Ekim 2014 *iletișim: Nilüfer Ersan, Yeditepe Üniversitesi Diș Hekimliği Fakültesi, Bağdat Cad. No: 238/3/A, 34728 Göztepe, İstanbul, Türkiye;

e-posta: nilufer.ersan@yeditepe.edu.tr

\section{Giriş}

Illk olarak 1652 yılında İtalyan bir cerrah olan Pietro Marchetti stilohyoid ligamentin kalsifiye olmasına bağlı olarak stiloid çıkıntıda uzama gözlemiş, stiloid çıkıntının anormal uzun olmasına veya stilohyoid ligamentin mineralizasyonuna bağlı stilalji ise ilk olarak Eagle tarafından 1937 yılında tanımlanmıştır. ${ }^{1,2}$ Eagle sendromunda kulağa doğru uzanan boğaz ağrısı, boğazda yabancı cisim hissi, disfaji, odinofaji, baş ağrısı, boyun rotasyonunda ağrı, baş dönmesi, tinnitus, dili çıkarmada ağrı, ağız açmada ağrı, çiğneme sırasında rahatsızlık, disfoni, seste geçici farklılaşma ve hipersalivasyon şeklinde semptomlar görülebilir. ${ }^{1}$ Stiloid çıkıntı $3 \mathrm{~cm}$ 'den fazla ölçüldüğünde uzamış olarak kabul edilmektedir. ${ }^{3-5}$ Stiloid çıkıntıda uzama, çift taraflı olarak daha yaygın görülmekle birlikte, semptomlar hemen her zaman tek taraflıdır.

Eagle sendromu tanısı, klinik ve radyolojik incelemelerle birlikte konulmaktadır. Son zamanlarda, kraniyofasiyal bölgedeki anatomik yapıların uzunluğunun tam olarak ölçülebildiği üç-boyutlu konik ışınlı bilgisayarlı tomografi yeni ve alternatif bir yöntem olarak sunulmuştur. ${ }^{6}$

Eagle sendromunun cerrahi olmayan tedavisi nonsteroidal antienflamatuar ilaçlar, analjezikler, antikonvülsanlar, antidepresanlar ve steroid veya anestetik ajanların lokal infiltrasyonudur. ${ }^{7}$ Eagle sendromunun kesin tedavisi stiloidin intraoral veya ekstraoral yaklaşımla cerrahi eksizyonudur. ${ }^{8}$

Bu olgu sunumunda, anamnez ve klinik muayene ile Eagle sendromundan şuphelenilen ve konik ışınlı bilgisayarlı tomografi ile kesin tanısı konulan bir olgu sunulmuş, Eagle sendromu tanısında radyolojik görüntülemenin önemi vurgulanmıştır.

\section{Olgu Bildirimi}

43 yaşındaki kadın hasta yaklaşık 1 yıldır boynun sağ tarafında mandibulanın arkasından boynun yan tarafına doğru uzanan, tek tarafı, zaman zaman yutma güçlüğüne yol açan ve yabancı cisim hissi veren, görsel ağrı skalasına göre 10 şiddetindeki ağrı şikayeti ile kliniğimize başvurdu. Hasta daha önce kulak-burun- 
boğaz, nöroloji ve ağrı kliniklerine başvurduğunu, çeşitli tedaviler uygulandığını ancak şikayetlerinin geçmediğini belirtti. Daha sonra diş hekimine başvuran hastaya yine hatalı tanı konularak analjezik ve antibiyotik reçete edilmiş ve yapılan dental tedavilere ek olarak temporomoandibuler eklem tedavisi uygulanmıştır. Hastanın alınan anamnezinde sistemik bir hastalığı olmadığı ve daha önce herhangi bir operasyona veya servikal bölgeye yönelik bir travmaya maruz kalmadığı öğrenildi. Yapılan klinik muayenede ağız açmada ve boyun hareketlerinde ağrı ve kısıtılık olduğu görüldü. Ağız içi incelemede ağrı şikayetine neden olabilecek herhangi bir dental probleme rastlanmadı. Palpasyonda sağ ve sol tonsiller fossalarda stiloid çıkıntıda uzama hissedildi, sadece sağ tarafta ağrılı olduğu görüldü ve tanıda Eagle sendromundan şüphelenildi. Hasta onamı alındıktan sonra radyolojik inceleme için yönlendirildi. Dental durumun kontrolü için alınan panoramik filmde 14 ve 45 no'lu eksik kanal tedavili ve kronik apikal periodontitisli dişler dışında herhangi bir dental problem olmadığı belirlendi. Bu dişlere yönelik yapılan dikey perküsyon ve palpasyonda ağrı saptanmadı. Bunun dışında şikayetlere sebep olabilecek diş kaynaklı herhangi bir probleme rastlanmadı, ancak çift taraflı olarak stiloid çıkıntılarda uzama gözlendi (Resim 1). İleri görüntüleme için konik ışınlı bilgisayarlı tomografi ile yapılan incelemede sağ ve sol stilohyoid ligamentlerin hyoid kemik seviyesine kadar, yaklaşık olarak sağda $71.5 \mathrm{~mm}$, solda $69.6 \mathrm{~mm}$ ölçülen kalsifikasyonu izlendi (Resim 2; Iluma, Imtec Imaging, Ardmore, OK, ABD; 120 kVp, 3.8 mA, voksel boyutu: 0.2 $\mathrm{mm}$, ışınlama süresi: $40 \mathrm{sn}$ ). Sağda stilohyoid ligamentin hyoid kemiğe yapışma yerinde kalsifiye olduğu izlendi. Ayrıca sağ tarafta atlas kemiğinin transvers çıkıntısının kalsifiye stilohyoid ligament ile çok yakın ilişkide olduğu görüldü (Resim 3). Semptomatik tedavinin etkili olmadığı hasta, cerrahi rezeksiyon için kulakburun-boğaz kliniğine yönlendirildi. Cerrahi rezeksiyon sonrası hastanın şikayetlerinin kaybolduğu görüldü (Resim 4).

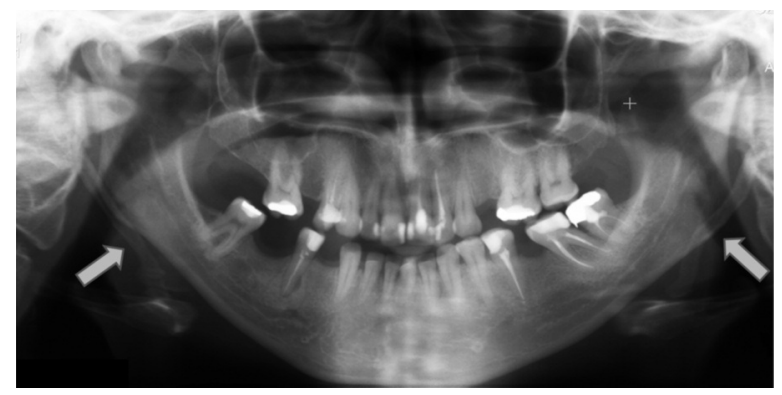

Resim 1. Panoramik radyografide çift taraflı uzamış stiloid çıkıntı okla gösterilmektedir.

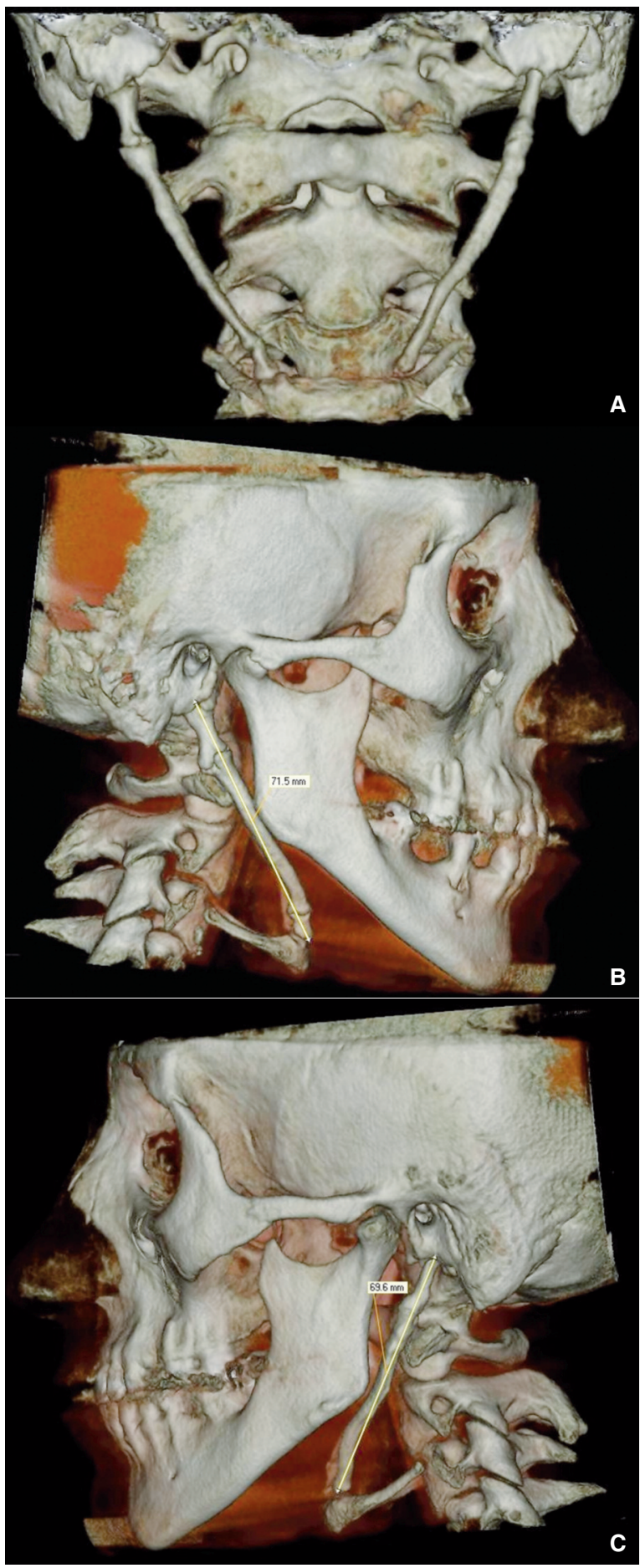

Resim 2. Konik ışınlı bilgisayarlı tomografide çift taraflı, hyoid kemiğe kadar uzanan uzamış stiloid çıkıntı (A), sağ ve sol taraftaki uzamış stiloid çıkıntıya yönelik ölçüm (B ve $C)$

\section{TARTIŞMA}

Eagle sendromu, uzun stiloid çıkıntı veya kalsifiye stilohyoid ligamentin sebep olduğu, kraniyal sinirlerin uyarılmasına sekonder ağrı ile karakterize, boğazda ve servikofasiyal bölgede kulağa, boyuna, temporomandi- 


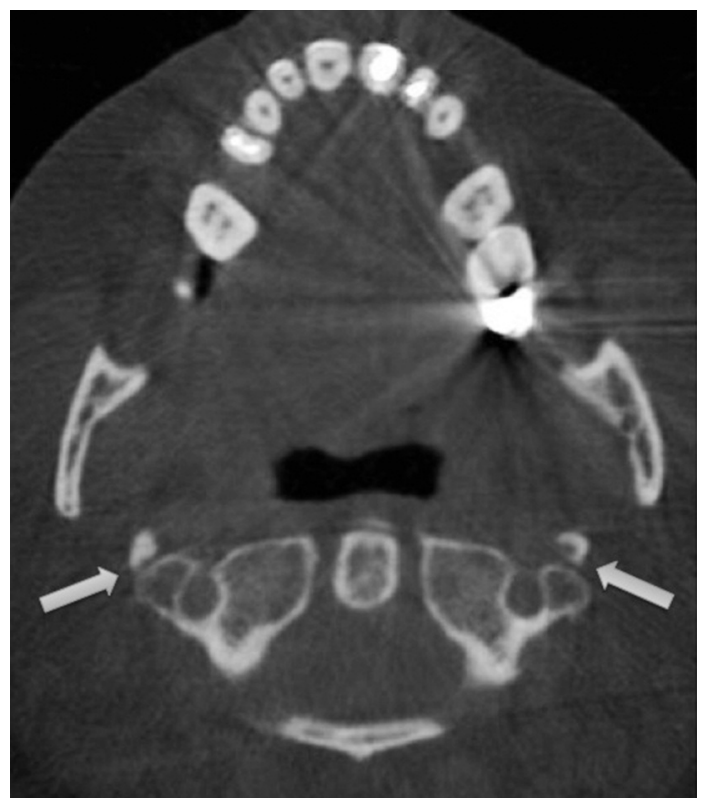

Resim 3. Aksiyal kesitte atlas kemiğinin transvers çıkıntıları ile uzamış stiloid çıkıntılar arasındaki ilişki

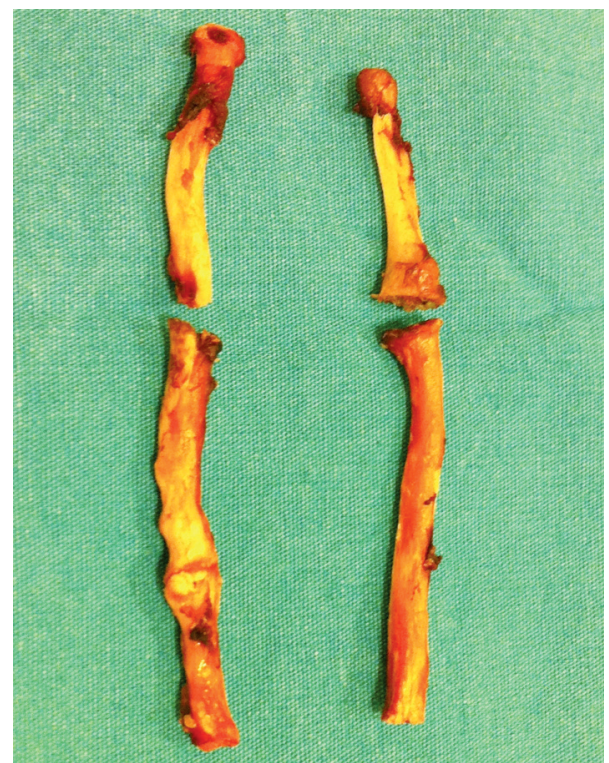

Resim 4. Cerrahi olarak eksize edilmiş uzun sağ ve sol kalsifiye stilohyoid ligamentler

buler ekleme veya üst ekstremiteye yayılabilen, baş pozisyonuyla değişebilen ağrı, yutma güçlüğü ve boğazda yabancı cisim hissi verebilen bir hastalıktır. ${ }^{5}$

Stiloid çıkıntı, temporal kemiğin alt yuzunde, stilomastoid deliğin önunde yerleşmiş silindirik şekilli kemik yapıdır ve stilohyoid ligament olarak devam ederek hyoid kemiğin küçük boynuzuna yapışır. Kartilajenöz kaynaklı olmasından dolayı ligamentin mineralize olma potansiyeli bulunmaktadır. ${ }^{9}$ Stiloid çıkıntının uzaması veya stilohyoid ligamentin ossifikasyonu kafa tabanından aşağıya doğru ve genellikle çift taraflı olmaktadır.
Stiloid çıkıntının apeksi, internal ve eksternal karotid arterler arasında uzanması nedeniyle klinik olarak önemlidir. Glossofaringeal sinir, jugular foramene yakın uzanarak stiloid çıkıntının hemen altından geçerken, aksesuar ve vagus sinirleri de stiloid çıkıntının medialinden geçer. ${ }^{1}$

Birçok araştırıcı normal stiloid çıkıntı uzunluğu hakkında farklı görüş öne sürmüş ve 20-45 mm arasında stiloid çıkıntı uzunluğu normal olarak kabul edilmiştir.4,10${ }^{13}$ Olgumuzda göruntalenen stiloid çıkıntı, sağda 71.5 $\mathrm{mm}$ ve solda $69.6 \mathrm{~mm}$ olarak ölçülmüş ve her ikisi de stilohyoid ligamentin kalsifikasyonu olarak değerlendirilmiştir.

Literatürde stiloid çıkıntıda uzama insidansı \%1.4\%30 arasında değişmektedir. ${ }^{8,10}$ Corell ve ark. ${ }^{14}$ yaptıkları çalışmada stiloid çıkıntıda uzama sıklığını \%18.2 olarak saptamış ve bunların \%93'unün çift taraflı olduğunu bildirmişlerdir. Stiloid çıkıntının uzun olması, semptom görülme insidansının düşük olması nedeniyle, Eagle sendromunun patogenezini açıklamakta tek başına yeterli olmamaktadır. Tonsillektomi gibi cerrahi işlemlerin ve lokal kronik irritasyonların stilohyoid kompleksin reaktif kemikleşen hiperplazisine neden olduğunu ileri sürülmüştür. ${ }^{1,3}$ Ancak Fritz, 43 olgudan sadece 11'inin tonsillektomi operasyonu geçirmiş olduğunu rapor etmiştir. ${ }^{15}$ Olgumuzda herhangi bir geçirilmiş operasyon hikayesi bulunmamaktadır.

Ossifikasyon derecesiyle semptomların şiddeti arasında doğrudan bir ilişki bulunamamıştır. Bazı araştırıcılar semptomların, stiloid çıkıntı ve çevre dokular arasındaki anatomik ilişkiye bağlı geliştiğini bildirmişlerdir. ${ }^{16}$ Thot ve ark. ${ }^{17}$ ise uzunluğun tek başına bir risk faktörü olmadığını, bununla birlikte uzamış stiloid çıkıntının anteriora ve mediale deviasyonunun bu sendromun en büyük sebebi olduğunu öne sürmüştür. Loeser \& Cardwell, ${ }^{18}$ çene şeklindeki ve ilk boyun omuru olan atlas kemiğinin transvers çıkıntısının uzunluk ve pozisyonundaki farklılıkların semptomlara sebep olabileceğini öne sürmüşlerdir.

Bazı araştırıcılar kadın ve erkeklerde görülme sıklığının değişmediğini, bazıları ise kadınlarda erkeklerden daha sık olduğunu rapor etmişlerdir. ${ }^{9}$ Bazı araştırıcılar yaşla birlikte stiloid çıkıntı uzunluğunun arttığını ve çoğunlukla 50 yaşın ustunde göruldüğü bildirmiştir;,4,9,19 ancak Correll ve ark. ${ }^{14}$ böyle bir ilişki olmadığını göstermiştir.

Toplumda Eagle sendromu sıklığının \%4-7 arasında olduğu bildirilmiştir. ${ }^{2,3}$ Bazı hastalarda radyolojik olarak stiloid çıkıntıda uzama saptanmasına rağmen semptomlar görulmeyebilir. Eagle, stiloid çıkıntıda uzama görülen hastalarda semptomların prevalansının $\% 0.16$ olduğunu öngörmüştür. ${ }^{3}$ Hastaların çok az bir yüzdesinin (\%1-\%5 arası) semptomatik olduğu rapor edilmiştir. ${ }^{1}$ Bilateral görulme sık olsa da semptomlar genelde uni- 
lateraldir. Bizim olgumuz 43 yaşında, kadın ve bilateral uzamış stiloid çıkıntıya sahip bir hastaydı. Konik ışınlı bilgisayarlı tomografide iki taraflı uzamış stiloid çıkıntı saptanmasına rağmen, semptomlar unilateraldi ve sadece stiloid çıkıntının daha uzun ve kalın olduğu sağ tarafta mevcuttu. Bu tarafta aynı zamanda kalsifiye stilohyoid ligament ile atlas kemiğinin transvers çıkıntısının çok yakın ilişkide olduğu gözlenmiştir.

Eagle sendromunun ayırıcı tanıları arasında servikal myofasiyal ağrı sendromu, migren, nevraljiler (trigeminal, glossofaringeal, nervus intermedius), nazofaringeal kitle/lezyon, tonsillitis, otitis, boyun ağrısına neden olan dejeneratif hastalıklar, psikosomatik hastalıklar, vasküler bozukluklar (ateroskleroz), laringofaringeal disestezi, sfenopalatin ganglion nöraljisi, kronik tonsillofarenjit, hyoid bursit, Sluder's sendromu, histamin sefalji, kume tipi başağrısı, özofagus divertikülü, temporal arterit, servikal omurga artriti, benign veya malign neoplazmlar, dental kaynaklı ağrılar ve temporomandibuler eklem problemleri ayırıcı tanıda daşunaıımelidir. ${ }^{8} \mathrm{Bu}$ yakınmalarla gelen hastalarda semptomların değişken ve nonspesifik olması nedeniyle Eagle sendromu gözden kaçabilmekte ve hastalar genellikle aile hekimi, otolaringolojist, nörolojist, sinir cerrahı, diş hekimleri, maksillofasiyal cerrahlar ve psikiyatristler tarafından görülmektedirler. Hatalı tanı konulan hastalar birçok gereksiz tedavi ve cerrahi uygulamalara maruz kalabilmektedirler. ${ }^{8}$ Burada sunduğumuz hasta da kliniğimize gelmeden önce kulak-burun-boğaz, nöroloji ve ağrı kliniklerine başvurmuştu; hatalı tanı sonucu çeşitli tedaviler uygulanmıştı ancak şikayetleri geçmemişti. Daha sonra diş hekimine başvuran hastaya yine hatalı tanı sonrasında temporomandibuler eklem tedavisi uygulanmıştı. Tedaviye cevap vermeyen kafa-yüz ağrıları veya baş-boyun bölgesinin sebebi açıklanamayan nörolojik şikayetlerinin varlığında ayırıcı tanıda Eagle sendromu düşünülmelidir.

Eagle sendromunun diğer benzer semptomlar gösteren durumlarla ayırt edilebilmesi için klinik tanıda genel olarak 3 kriter belirlenmiştir: Yutkunma ile artan karakteristik künt, sürekli bir ağrı, tonsiller fossada palpe edilebilen uzamış stiloid çıkıntı ve panoramik film veya bilgisayarlı tomografide $30 \mathrm{~mm}$ 'den uzun ölçülen stiloid çıkıntı varlığı.

Uzamış stiloid çıkıntı tanısında farklı görüntüleme yöntemleri kullanılmıştır. Panoramik radyografide lineer ossifikasyonun mastoid çıkıntıdan başlayıp ramusun posteroinferior tarafından geçerek hyoid kemiğe uzandığı görülmektedir. Ancak diğer anatomik yapıların superpozisyonu, distorsiyona sebep olması ve açılanmaya bağlı olarak boyutlarda magnifikasyon oluşması stiloid kompleksin panoramik filmde görünen uzunluğunu etkileyebilmekte ve tanıda güçlük oluşturmaktadır. ${ }^{16,19}$ Üç-boyutlu bilgisayarlı tomografi, rekonstrüksiyonunda magnifikasyon etkilerine ve süperpozisyona bağlı hatalar bulunma- ması gibi nedenlerle radyolojik tanıda altın standart olarak kabul edilmektedir. Konik ışınlı bilgisayarlı tomografi, maksillofasiyal radyografik görüntülemede medikal bilgisayarlı tomografiler ile kıyaslandığında daha düşük doz olması nedeniyle tercih edilmektedir. Konik ışınlı bilgisayarlı tomografi ile elde edilen görüntüler, stiloid çıkıntı uzunluğunu, oryantasyonunu ve anatomik ilişkilerinin değerlendirilmesini sağlar ve anatominin anlaşılması, doğru bir cerrahi planlamanın yapılması ve hastaya hastalığının açıklamasında objektif bir tanı aracıdır. ${ }^{20}$ Olgumuzda stiloid çıkıntılar ortopantomogram ve konik ışınlı bilgisayarlı tomografi ile tanımlanmış, kesin uzunluklar konik ışınlı bilgisayarlı tomografi ile ölçulmüştür.

Eagle sendromunun tedavisi hastanın rahatsızlık derecesine göre değişse de birçok olguda cerrahi rezeksiyondur. ${ }^{3,8}$ Bizim olgumuzda cerrahi rezeksiyon sonrasında hastanın semptomlarında gerileme görülmüştür.

\section{SonUç}

Mandibulanın arkasından boynun yan tarafına doğru uzanan, tek taraflı, zaman zaman yutma güçlüğüne yol açan ve yabancı cisim hissi veren bir şikayetle başvuran ağrılı hastaya konik ışınlı bilgisayarlı tomografi ile Eagle sendromu tanısı konulmuştur. Eagle sendromu, basit bir rahatsızlıktan hayatı tehdit eden yaralanmalara kadar pekçok komplikasyona neden olabilen, ender görülen bir durumdur. Boyun, boğaz, kulak, diş, temporomandibuler eklem ağrıları; yutma gạçlağa, boğazda yabancı cisim hissi gibi yakınmalar bir diş hekiminin ganlak pratiğinde karşılaşabileceği sorunlardır. Non-spesifik semptomlar vermesi nedeniyle tanı konulması zordur. Bu tip yakınmaları olan hastalarda, özellik yakınmaların tedavilere dirençli olması halinde, stiloid çıkıntıda uzama bir etiyolojik neden olarak akılda tutulmalıdır. Konik ışınlı bilgisayarlı tomografi ayırıcı tanıda detaylı bilgi vermektedir. Cerrahi rezeksiyon, Eagle sendromu görülen hastalar üzerinde etkin bir tedavi yöntemidir.

\section{TEŞEKKÜR VE ANMA}

Katkılarından dolayı İstanbul Tıp Fakültesi Hastanesi'nde görev yapmakta olan Kulak Burun Boğaz uzmanı Uzm. Dr. Bora Başaran'a teşekkürlerimizi sunarız.

Bu makale daha önce poster olarak sunulmuş (17th International Congress on Oral Pathology and Medicine, 25-30 Mayıs 2014, İstanbul, Türkiye), özeti ise Oral Surgery, Oral Medicine, Oral Pathology, Oral Radiology adlı dergide yayımlanmıştır (Ersan N, İlgüy M, İlgüy D. Facial Pain Due to Elongated Styloid Process: A Case Report and Literature Review. Oral Surgery, Oral Medicine, Oral Pathology, Oral Radiology, 03/2015; 119(3):e219. DOI:10.1016/j.00oo.2014.07.521).

Çıkar çatışması: Yazarlar bu çalışmayla ilgili herhangi bir çıkar çatışmalarının bulunmadığını bildirmişlerdir. 


\section{KAYNAKLAR}

1. Fini G, Gasparini G, Filippini F, Becelli R, Marcotullio D. The long styloid process syndrome or Eagle's syndrome. J Craniomaxillofac Surg 2000;28:123-7.

2. Eagle WW. Elongated styloid process. Report of two cases. Arch Otolaryngol 1937;25:584-7.

3. Eagle WW. Elongated styloid process: symptoms and treatment. Arch Otolaryngol 1958;67:172-6.

4. Monsour PA, Young WG. Variability of the styloid process and stylohyoid ligament in panoramic radiographs. Oral Surg Oral Med Oral Pathol 1986;61:522-6.

5. Ilgüy M, Ilgüy D, Güler N, Bayirli G. Incidence of the type and calcification patterns in patients with elongated styloid process. J Int Med Res 2005;33:96-102.

6. Scarfe WC, Farman AG, Sukovic P. Clinical applications of conebeam computed tomography in dental practice. J Can Dent Assoc 2006;72:75-80.

7. Slavin KV. Eagle syndrome: entrapment of the glossopharyngeal nerve? Case report and review of the literature. J Neurosurg 2002,97:216-8.

8. Mayrink G, Figueiredo EP, Sato FR, Moreira RW. Cervicofacial pain associated with Eagle's syndrome misdiagnosed as trigeminal neuralgia. Oral Maxillofac Surg 2012;16:207-10.

9. Keur JJ, Campbell JP, McCarthy JF, Ralph WJ. The clinical significance of the elongated styloid process. Oral Surg Oral Med Oral Pathol 1986;61:399-404

10. Kaufman SM, Elzay RP, Irish EF. Styloid process variation: radiologic and clinical study. Arch Otolarngol 1970;91:460-3.

11. Ilgüy $D$, Ilgüy $M$, Fişekçioğlu $E$, Dölekoğlu $S$. Assessment of the stylohyoid complex with cone beam computed tomography. Iran J Radiol 2012;10:21-6.

12. Jung $T$, Tschernitschek H, Hippen H, Schneider B, Borchers L. Elongated styloid process: when is it really elongated? Dentomaxillofac Radiol 2004;33:119-24.

13. Mehta AK, Ravikumar R. Anomalous elongation of styloid process. Medical Journal Armed Forces India 2000;56:248-9.

14. Correll RW, Jensen JL, Taylor JB, Rhyne RR. Mineralization of the stylohyoid-stylomandibular ligament complex. A radiographic incidence study. Oral Surg Oral Med Oral Pathol 1979;48:286-91.

15. Fritz M. Elongated styloid process: cause of obscure throat symptoms. Arch Otolaryngol 1940;31:911-8.

16. Anbiaee N, Javadzadeh A. Elongated styloid process: is it a pathologic condition? Indian J Dent Res 2011;22:673-7.

17. Thot B, Revel S, Mohandas R, Rao AV, Kumar A. Eagle's syndrome. Anatomy of the styloid process. Indian J Dent Res 2000;11:65-70.

18. Loeser LH, Cardwell EP. Elongated styloid process, a case of the glosso-pharyngeal neuralgia. Arch Otolaryngol 1942;31:198-202.
19. Ferrario VF, Sigurtá D, Daddona A, Dalloca L, Miani A, Tafuro F, et al. Calcification of the stylohyoid ligament: Incidence and morphoquantitative evaluations. Oral Surg Oral Med Oral Pathol 1990;69:524-9.

20. Nakamaru Y, Fukuda S, Miyashita S, Ohashi M. Diagnosis of the elongated styloid process by three-dimensional computed tomography. Auris Nasus Larynx 2002;29:55-7.

\section{Eagle syndrome: a case report}

\begin{abstract}
INTRODUCTION: Eagle syndrome, an uncommon sequela of elongation of the styloid process or calcification of the stylohyoid ligament, can manifest as pain in the face and the anterolateral neck, often with referred pain to the ear and the temporomandibular joint area.
\end{abstract}

CASE REPORT: A 43-year old female patient presented to our Dentomaxillofacial Radiology Department with complaints of unremitting unilateral facial and neck pain, limitation in the movement of the neck, sensation of foreign body in the throat, dysphagia, and otalgia for a year. Systemic anamnesis of the patient was unremarkable. In the clinical examination, digital palpation of the tonsillar fossa aggravated the pain. The patient was being treated for temporomandibular joint disorder. A panoramic radiograph taken after the clinical examination revealed bilateral styloid process elongation. Cone-beam computed tomography also revealed bilateral ossification of the stylohyoid ligament which was measured as $71.5 \mathrm{~mm}$ and $69.6 \mathrm{~mm}$ on the right and the left side, respectively; and the patient was diagnosed as having Eagle syndrome. The patient was referred to the otolaryngology clinic for surgical treatment. Surgical shortening of the structure provided definitive relief of the patient's symptoms.

CONCLUSION: In cases of unexplained complaints in the head and neck region Eagle syndrome should be considered in the differential diagnosis as it may have therapeutic consequences.

KEYWORDS: Cone-beam computed tomography; dysphagia; Eagle syndrome 